\title{
THE SIGNIFICANCE OF THE VESSELS OF THE SKIN IN ESSENTIAL HYPERTENSION
}

\author{
By J. MURRAY STEELE AND ESBEN KIRK
}

(From the Hospital of the Rockefeller Institute for Medical Research, New York City)

(Received for publication July 2, 1934)

Evidence of a varied nature has led to the widely accepted conclusion that one of the significant factors leading to elevation of the blood pressure in essential hypertension is constriction of the arterioles. A thorough review of the literature dealing with this problem has recently been published by Fishberg (1) and tends to show that the most important vascular territory involved in this mechanism is the splanchnic region.

The evidence is, as has been said, varied. As long ago as $1875 \mathrm{Litten}$ (2) observed that tying off the superior mesenteric artery in dogs was followed promptly by rise of arterial pressure of from twenty to twenty-five millimeters of mercury. The elevation frequently persisted for several hours. Longcope and McClintock $(3,4)$ demonstrated that compression of the coeliac axis and superior mesenteric arteries in dogs is followed by temporary increase of the blood pressure. Jansen, Tams and Achelis (5) repeated these experiments and essentially confirmed their results. They observed further that cold colonic irrigations in normal individuals were followed by much greater rises in blood pressure than were cold baths although in the case of colonic irrigations constriction probably involved only the colonic section of the splanchnic vessels, whereas in cold baths nearly all the vessels of the skin were affected. They found that binding the extremities of normal persons with elastic bandages caused only an insignificant rise in blood pressure but that in individuals suffering from essential hypertension it was attended by marked elevation of the arterial tension. This phenomenon was interpreted as indicating that in patients with arterial hypertension reduction in the degree of distensibility of the splanchnic vessels resulted in failure to attain normal compensatory dilatation following constriction of peripheral vessels. In extensive studies on the action of pressor substances prepared from the plasma of normal and hypertensive individuals Page (6) found likewise that it was constriction of the blood vessels of the splanchnic region that was chiefly responsible for rise in blood pressure on injection of such substances into animals. Similarly, it has long been known that the vessels of the splanchnic region are most important in the rise of blood pressure following injections of adrena- 
lin. On the other hand many observations in patients with thrombo-angiitis obliterans substantiate the conclusions of Jansen, Tams and Achelis that no relation exists between the narrowing of the arterioles of the extremities and the level of systemic blood pressure (1). It has been repeatedly demonstrated in this clinic, moreover, that attacks of spastic contractions of peripheral arteries resulting in numbness and paleness of the skin-a common occurrence in patients with essential hypertension-are not accompanied by rise in arterial pressure.

In interpreting experiments in animals it should be emphasized, however, as do Meyer and Gottlieb (7) that the reactions of the vessels of the skin in human beings may differ widely from those of the vessels of the skin in fur-bearing animals.

Although the results of previous investigations appear to indicate that the vessels of the skin do not participate in the mechanism which results in elevating the blood pressure in essential hypertension it seemed desirable to test this view with evidence of a different nature. Since the temperature of the surface of the body depends almost entirely upon the flow of blood to the skin, measurements of surface temperature were undertaken over a 30-hour period under uniform conditions to secure new information on the behavior of the arterioles in this malady.

The technique and conditions of measurement of surface temperature together with data obtained by this technique in normal individuals have been published (8). In this study the behavior of the vessels in the skin of nine individuals, three males and six females, suffering from arterial hypertension was investigated. Their ages fell between 29 and 48 years. They were selected because evidence of heart failure, of diminution in function of the kidneys as measured by the urea clearance test of Van Slyke, and of arteriosclerosis was absent. The duration of hypertension varied from eighteen months to five years. Several cases represented the type usually designated as " malignant hypertension."

It is evident (Fig. 1) that the form of the curve of surface temperature in the hypertensive group during a twenty-four-hour period is similar to that of normal individuals and that the level of the two groups is approximately the same. It follows that the average temperature of both groups for the whole period is also the same (Table I). No significant alteration in either systolic or diastolic arterial pressure was observed furthermore during the diurnal changes in surface temperature in the group as a whole or in any individual case. When the arterial pressure is high some increase in tone of the peripheral vessels must develop in order to maintain a normal flow of blood through the skin. That the latter is true is shown by the fact that the temperature of the skin is normal. If there were no increase in arterial tone in the presence of high arterial tension, increased flow of 


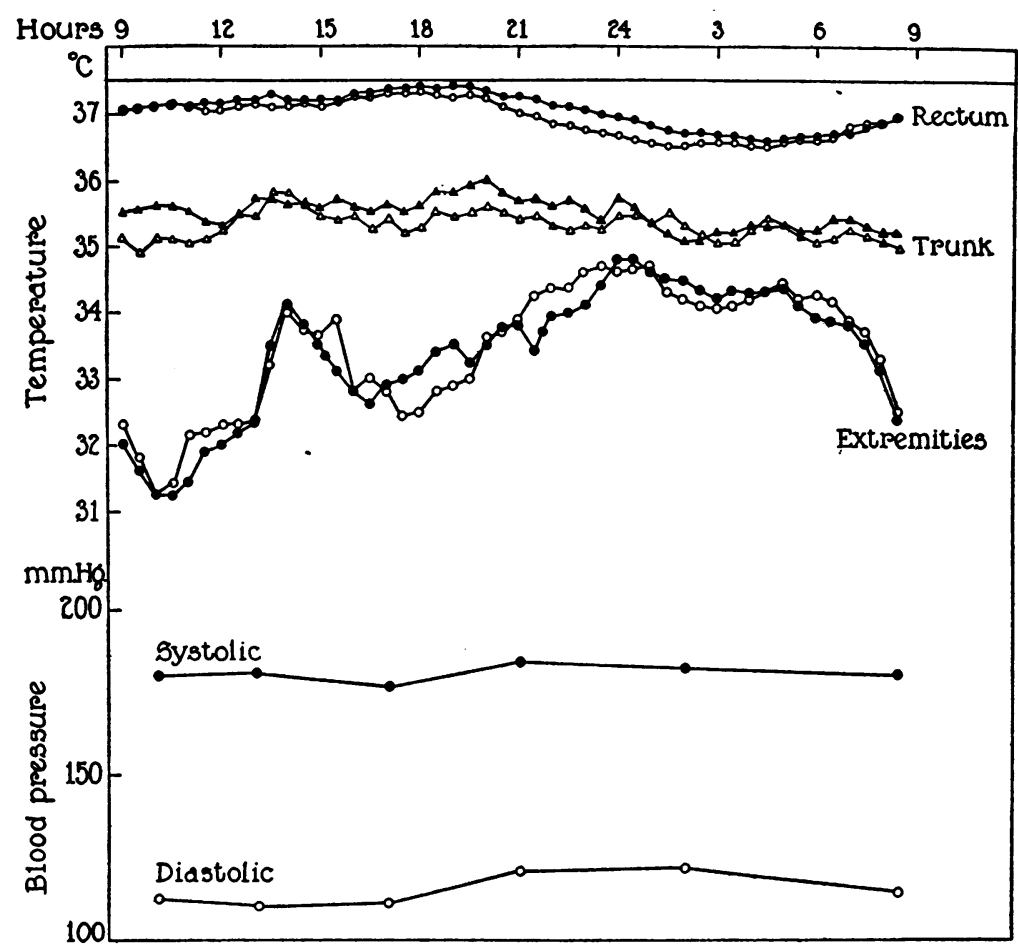

Fig. 1. Figures for the Average Temperatures of the Designated Locations in the Group of Normal Individuals are Charted in Solid Symbols; Those for the Group of Hypertensive Individuals in Open ONES.

blood through the skin would result in excessive loss of heat. The slight increase in tone of the arterioles of the skin may be regarded, therefore, as dependent upon, rather than antecedent to, general arterial hypertension.

\section{CONCLUSIONS}

1. The temperature of the skin of individuals suffering from arterial hypertension does not differ significantly from that of normal individuals.

2. Diurnal variations in surface temperature regularly occur in individuals with arterial hypertension without significant change in arterial pressure.

3. Elevation of arterial pressure in hypertensive individuals does not depend on, though it may be accompanied by, constriction of the arterioles of the skin. 


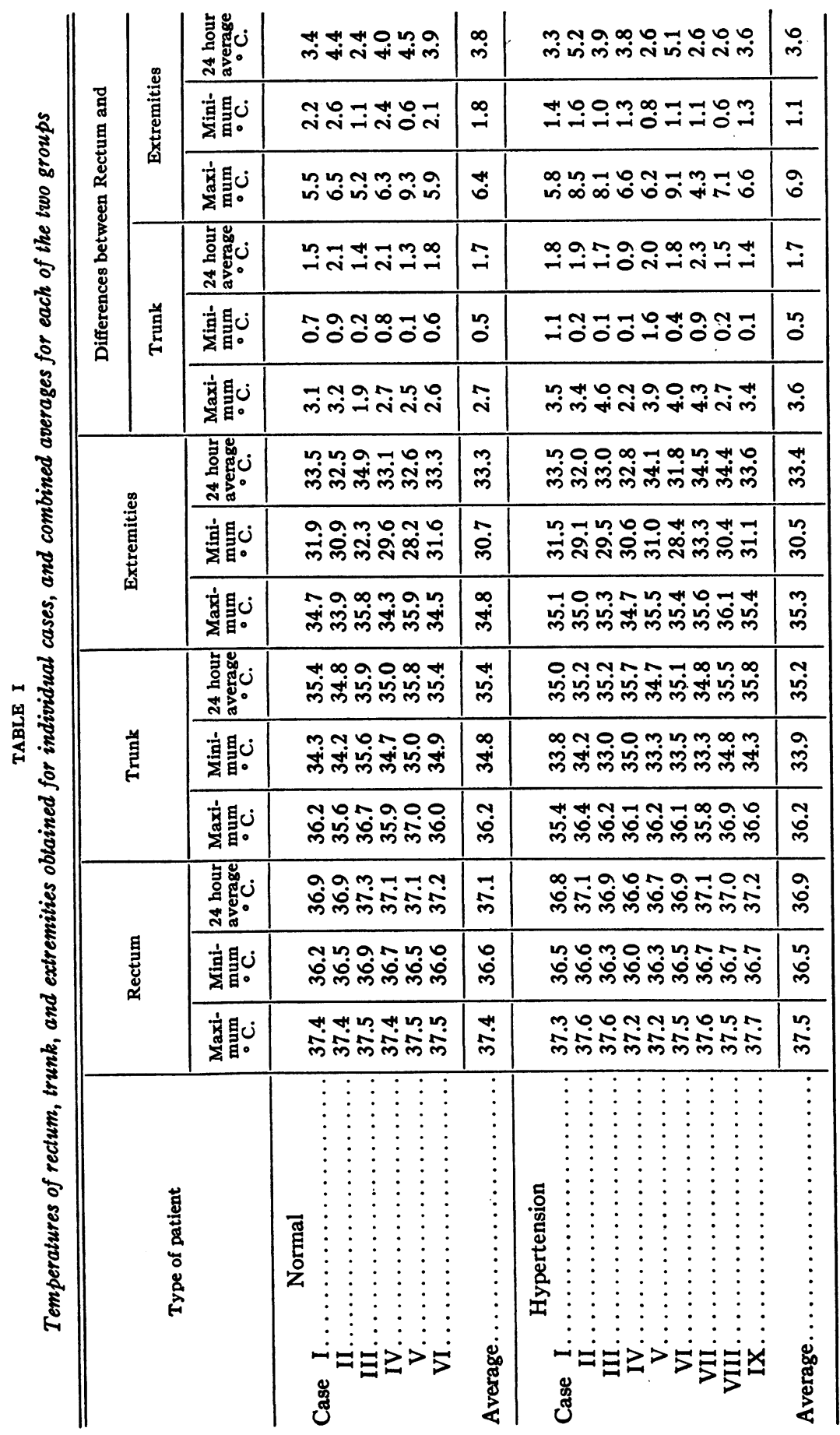




\section{BIBLIOGRAPHY}

1. Fishberg, A. M., Hypertension and Nephritis. Lea and Febiger, Philadelphia, 1934, 3d ed.

2. Litten, M., Ueber die Folgen des Verschlusses der Arteria mesaraica superior. Arch. f. path. Anat. u. Physiol., 1875, 63, 289.

3. Longcope, W. T., and McClintock, A. T., The effect of compression of the superior mesenteric artery upon the systemic blood pressure. Univ. Penn. Med. Bull., 1909, 22, 226.

4. Longcope, W. T., and McClintock, A. T., The effect of permanent constriction of the splanchnic arteries and the association of cardiac hypertrophy with arteriosclerosis. Arch. Int. Med., 1910, 6, 439.

5. Jansen, W. H., Tams, W., and Achelis, H., Blutdruckstudien I. Zur Dynamik des Blutdrucks (nach experimentellen Untersuchungen an Mensch und Tier). Deutsches Arch. f. klin. Med., 1924, 144, 1.

6. Page, I. H., Personal communication.

7. Meyer, H. H., and Gottlieb, R., Die experimentelle Pharmakologie als Grundlage der Arzneibehandlung. Urban and Schwarzenberg, Berlin, 1921, 5th ed., page 303 .

8. Steele, J. M., Fever in heart failure. Relations between the temperature of the interior and the surface of the body. J. Clin. Invest., 1934, 13, 869. 